\title{
Target Groups for Organic Wine The Importance of Segmentation Analysis
}

\author{
Janssen, Meike; Schäufele, Isabel; Zander, Katrin
}

Document Version

Accepted author manuscript

Published in:

Food Quality and Preference

DOI:

10.1016/j.foodqual.2019.103785

Publication date:

2020

License

CC BY-NC-ND

Citation for published version (APA):

Janssen, M., Schäufele, I., \& Zander, K. (2020). Target Groups for Organic Wine: The Importance of Segmentation Analysis. Food Quality and Preference, 79, [103785].

https://doi.org/10.1016/j.foodqual.2019.103785

Link to publication in CBS Research Portal

\section{General rights}

Copyright and moral rights for the publications made accessible in the public portal are retained by the authors and/or other copyright owners and it is a condition of accessing publications that users recognise and abide by the legal requirements associated with these rights.

Take down policy

If you believe that this document breaches copyright please contact us (research.lib@cbs.dk) providing details, and we will remove access to the work immediately and investigate your claim. 


\section{Target Groups for Organic Wine: The Importance of Segmentation Analysis}

\section{Meike Janssen, Isabel Schäufele, and Katrin Zander}

Journal article (Accepted manuscript*)

\section{Please cite this article as:}

Janssen, M., Schäufele, I., \& Zander, K. (२०२०). Target Groups for Organic Wine: The Importance of Segmentation Analysis. Food Quality and Preference, 79, [103785]. https://doi.org/10.1016/j.foodqual.2019.103785

DOI: https://doi.org/10.1016/.j.foodqual.2019.103785

* This version of the article has been accepted for publication and undergone full peer review but has not been through the copyediting, typesetting, pagination and proofreading process, which may lead to differences between this version and the publisher's final version AKA Version of Record.

Uploaded to CBS Research Portal: August २०२०

(C) २०19. This manuscript version is made available under the CL-BY-NC-ND 4.0 license http://creativecommons.org/licenses/by-nc-nd/4.0/ 


\section{Journal Pre-proofs}

Target groups for organic wine: The importance of segmentation analysis

Meike Janssen, Isabel Schäufele, Katrin Zander

PII:

S0950-3293(19)30148-X

DOI: https://doi.org/10.1016/j.foodqual.2019.103785

Reference:

FQAP 103785

To appear in:

Food Quality and Preference

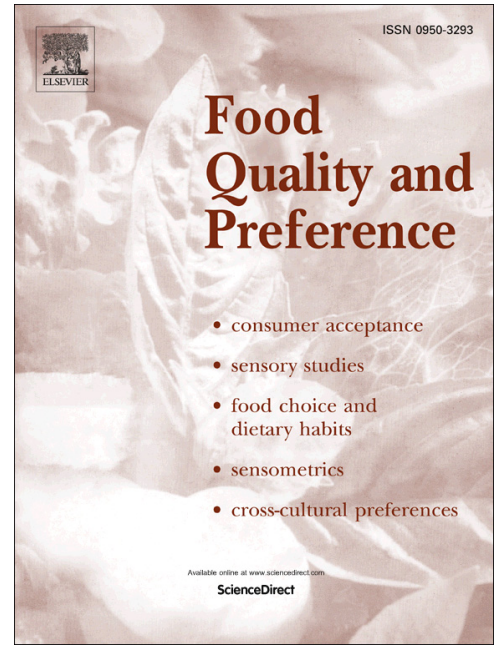

Received Date: $\quad 28$ February 2019

Revised Date: $\quad 26$ August 2019

Accepted Date: $\quad 29$ August 2019

Please cite this article as: Janssen, M., Schäufele, I., Zander, K., Target groups for organic wine: The importance of segmentation analysis, Food Quality and Preference (2019), doi: https://doi.org/10.1016/j.foodqual.2019.103785

This is a PDF file of an article that has undergone enhancements after acceptance, such as the addition of a cover page and metadata, and formatting for readability, but it is not yet the definitive version of record. This version will undergo additional copyediting, typesetting and review before it is published in its final form, but we are providing this version to give early visibility of the article. Please note that, during the production process, errors may be discovered which could affect the content, and all legal disclaimers that apply to the journal pertain.

(C) 2019 Elsevier Ltd. All rights reserved. 
Target groups for organic wine:

The importance of segmentation analysis

Meike Janssen $^{1}{ }^{*}$, Isabel Schäufele ${ }^{2}, \&$ Katrin Zander ${ }^{3}$

${ }^{1}$ Department of Management, Society and Communication

Copenhagen Business School

Dalgas Have 15, 2000 Frederiksberg, Denmark

mj.msc@cbs.dk

${ }^{2}$ Department of Agricultural and Food Marketing

University of Kassel

Steinstrasse 19, 37213 Witzenhausen, Germany

i.schaeufele@uni-kassel.de

${ }^{3}$ Thünen-Institute of Market Analysis

Bundesallee 63, D-38116 Braunschweig

katrin.zander@thuenen.de 
*corresponding author:mj.msc@cbs.dk 
Target groups for organic wine: The importance of segmentation analysis

\begin{abstract}
In light of low and stagnating market shares of organic wine, there is an ongoing debate about growth potential for organic wine. A recent study revealed that even consumers of organic food did not necessarily purchase organic wine regularly. The aim of this contribution was to analyse the wine preferences of organic food consumers and identify promising new target groups for organic wine. We conducted choice experiments in Germany $(\mathrm{N}=600)$ and analysed the data with mixed logit models and latent class models, revealing interesting differences between the results of the two approaches. While the mixed logit models suggested 'organic' was the most important wine attribute, the latent class models challenged this proposition. While three of four consumer segments had a strong preference for organic, only one segment in the red wine model (and no segment in the white wine model) gave organic highest priority. Just like non-organic consumers, many organic food consumers seem to use price or country of origin as the most important quality cue for wine. The comparison between the results of the choice experiments and the participants' stated normal purchase behaviour suggested there is growth potential for organic wine. Apparently, consumers of organic food would buy more organic wine if their preferred type and variety of conventional wine would be available in organic quality at similar price levels.
\end{abstract}

\title{
Keywords
}

Organic; wine; food; latent class analysis; mixed logit model; choice experiments

\section{Introduction}

The production of grapes and wine causes many environmental issues. The use of chemical vineyard inputs, i.e. synthetic fertilisers, pesticides and herbicides, is one of the key areas of environmental concern (Christ and Burritt, 2013). Organic wine production focuses on the avoidance of these chemicals (United States Department of Agriculture, 2000; EU Commission, 2012) and contributes to the international sustainability movement in the wine sector (Mariani and Vastola, 2015).

Even though the global organic wine growing area achieved significant growth rates in recent years, it accounted for only 5\% of the total wine growing area in 2016 (Lernoud and Willer, 2018). At the same time, the market for organic wine is rather small compared to popular organic food products like eggs, milk and dairy products (Willer et al., 2018). In Germany - the third most important wine importing country in the world (Statista, 2018) - the market share 
for organic wine was stagnating at around 5\% between 2010 and $2016 .{ }^{1}$ Despite the relatively low relevance of organic wine in the overall wine market, many consumer studies identified a great potential for increasing organic wine purchases (Schäufele and Hamm, 2017).

In previous studies, the reasons why consumers were interested in organic wine were related to their beliefs regarding environmentalism (e.g. Bonn et al., 2016; D'Amico et al., 2016; Sogari et al., 2015) and personal health (Bonn et al., 2016; Brugarolas et al., 2010; D'Amico et al., 2016; Mann et al., 2012). Moreover, the belief in the superior taste of organic wine was an important determinant for the purchase of organic wine in some studies (Kim and Bonn, 2015; Wiedmann et al., 2014; Pagliarini et al., 2013). At the same time, organic wine had a rather negative image regarding taste, quality and value for money in other studies (Olsen et al., 2012; Stolz and Schmid, 2008; Hoffmann and Szolnoki, 2010).

In light of contrasting empirical findings on consumer perceptions of organic wine, there is an ongoing debate about growth potential of organic wine. Several authors of consumer studies concluded that price and origin were more important purchase criteria than production method (Bernabéu et al., 2008; Chiodo et al., 2011; Mann et al., 2012), while other studies emphasised the importance of the organic label as a cue for quality (Wiedmann et al., 2014; Pagliarini et al., 2013).

Interestingly, a recent study on wine consumption identified different consumer segments with high preferences for organic food but heterogeneous preferences and levels of price acceptance for organic wine, suggesting that the wine preferences of organic food consumers should be investigated further (Schäufele and Hamm, 2018). We argue that organic food consumers are the most interesting target group for organic wine, since these consumers are generally open to organic production and shop at retail outlets where organic wine is available.

The aim of this contribution was to analyse the wine preferences of organic food consumers and identify different segments of organic wine consumers. With the method of choice experiments, we determined the role organic production plays and identified the most important wine attributes. We compared the results of two different methods of data analysis - mixed logit models and latent class analysis - providing interesting insights into the limitations of mixed logit models in the case of consumer segments with partly opposite preference structures. The paper concludes with recommendations for increasing the market share of organic wine by targeting consumers of organic food.

\section{State of the art and hypotheses}

This section summarises existing knowledge on consumer preferences for different wine attributes and presents hypotheses on the importance consumers place upon the attribute 'organic' compared to other wine attributes.

Wine is a product category with a wide product range, not only in specialised wine stores but also in grocery stores. This is the result of the high number of wine producers in various

\footnotetext{
${ }^{1}$ Own compilation based on GfK household panel data documented in Boller and Hamm (2018) and Schäufele and Hamm (2018).
} 
countries and regions as well as diverse consumer preferences regarding quality and taste (Goldstein et al., 2008; Barreiro-Hurlé et al., 2008). Wine quality and taste are influenced by numerous factors, e.g. grape variety, micro-climatic conditions (like terroir, weather), and the wine-makers work in the cellar. When purchasing wine in grocery stores, it is often difficult for consumers to judge on wine quality and taste (Lockshin et al., 2006), which is why consumers mostly base their wine choice on extrinsic product attributes such as grape variety (Gustafson et al., 2016), origin (Defrancesco et al., 2012; Jaeger et al., 2013; Yang and Paladino, 2015), price (Panzone, 2014), brand and label design (Drennan et al., 2015).

In addition to these traditional wine attributes, the production method - i.e. organic, environmentally friendly, or sustainable production - has become a relevant attribute for some consumers in recent times (Schäufele and Hamm, 2017). Previous studies showed that consumer preferences for organic wine were driven by consumers' values and beliefs regarding environmentalism (Bonn et al., 2016; D'Amico et al., 2016; Kim and Bonn, 2015; Schäufele et al., 2018; Stolz and Schmid, 2008) and attitudes towards health (Bonn et al., 2016; Brugarolas et al., 2010; D'Amico et al., 2016; Fotopoulos et al., 2003; Mann et al., 2012; Stolz and Schmid, 2008); moreover, the belief in the superior taste and quality of organic wine was an important determinant in some studies (Kim and Bonn, 2015; Wiedmann et al., 2014; Pagliarini et al., 2013; Fotopoulos et al., 2003). It can thus be noted that the most important reasons for buying organic wine are the same as for organic food in general; also organic food consumption is largely driven by the desire for healthy and natural food, environmental friendly production methods, and tasty food (e.g. Janssen, 2018; Zanoli and Naspetti, 2002).

At the same time, previous studies also found that organic wine had a rather negative image regarding taste, quality and value for money among some consumer groups (Olsen et al., 2012; Stolz and Schmid, 2008; Hoffmann and Szolnoki, 2010). Sellers (2016) showed that the level of knowledge about wine culture had a negative impact on the willingness-to-pay a price premium for sustainable wine. Moreover, several studies showed that positive consumer perceptions of organic wine did not lead to respective action; the perception of organic wine as more environmental friendly had neither an effect on the purchase of organic wine (Kim and Bonn, 2015; Mann et al., 2012), nor on the consumption of organic wine (Mann et al., 2012), nor on the preference for organic wine (Rahman et al., 2014). Thus, evidence from previous consumer studies in combination with rather low market shares of organic wine lead to the assumption that other wine attributes are far more important to consumers than organic production.

The aim of the present study was to analyse the wine preferences of organic food consumers. The question was: When purchasing wine, how important is the attribute 'organic' in comparison to other wine attributes for organic food consumers? We argue that organic food consumers are the most interesting target group for increasing sales with organic wine, since these consumers are generally open to organic production and shop at retail outlets where organic wine is available. At the same time, a recent study on wine consumption identified growth potential of organic wine purchases among consumers of organic food, in that organically-minded consumers bought wine from conventional production to a considerable degree (Schäufele and Hamm, 2018; Schäufele et al., 2018). 
Regarding the question as to how important the attribute 'organic' is in comparison to other wine attributes for organic food consumers, the present study focused on 'price' and 'geographical origin' as two important extrinsic wine attributes (for details see " 3 . Methods and materials"). In the wine literature, there is generally consensus that 'price' and 'origin' are among the most important extrinsic product attributes for consumers. 'Price' is relevant for consumers not only because of its economic effect but also because of its role as an important quality cue, in that consumers generally assume that more expensive wines are of higher quality than cheaper wines (Lockshin et al., 2006; Goldstein et al., 2008).

Regarding the question whether the attribute 'organic' or the attributes 'price' and 'origin' have a stronger influence on consumers' wine choice, previous studies on organic and sustainable wine unanimously confirmed that production method only had a weak influence on consumer preferences (Bernabéu et al., 2008; Chiodo et al., 2011; Mann et al., 2012; Mueller Loose and Lockshin, 2013; Rahman et al., 2014; Schmit et al., 2013). 'Price' and 'origin' were more important purchase criteria than production method (Bernabéu et al., 2008; Chiodo et al., 2011; Mann et al., 2012). However, these findings referred to wine drinkers in general, not to organic food consumers. The wine literature also confirmed that knowledge about production methods (Brugarolas et al., 2010; Kim and Bonn, 2015; Pomarici and Vecchio, 2014; Vecchio, 2013; Sellers, 2016) and label awareness (Mueller Loose and Remaud, 2013) had a significant positive influence on preferences for organic and sustainable wine. Previous studies on drivers of organic food consumption found that organic food consumers know more about organic agricultural production methods and organic labels (Aertsens et al., 2009) and pay relatively little attention to food prices compared to average consumers (Lusk, 2011; Janssen, 2018). Therefore, we suggest the following hypothesis:

H1: For organic food consumers, the attribute 'organic' has a stronger influence on wine choice than 'price'.

With regards to geographical origin, several studies found a positive relationship between organic food consumption and the consumption of local and domestic food (Baker et al., 2004; Hempel and Hamm, 2016; Janssen, 2018; Padel and Foster, 2005). Other studies identified different consumer segments who regarded organic and local food either as complementary or supplementary (Gracia et al., 2014; Naspetti and Bodini, 2008). Given the fact that previous studies provided mixed findings, we suggest the following hypothesis:

H2: There are different segments of organic food consumers; for some segments the attribute 'organic' is more important than 'geographical origin', for other segments the opposite holds true.

With regards to the question as to whether 'price' or 'origin' is more important to consumers when choosing wine, there are mixed findings in the literature, depending on the study country and the origins and price levels under investigation. Many studies found that 'price' was more important than 'origin' (e.g. Soosay et al., 2012) while other studies suggested 'price' and 'origin' were rather equally important (e.g. Mann et al., 2012). Yet, other authors identified different consumer segments who used either 'price' or 'origin' as the main choice criterion for wine (e.g. Bernabéu et al., 2008). Again, the findings cited here referred to the general population of wine drinkers. The wine preferences of organic food consumers have not 
been investigated in detail so far. With regards to food choice in general, organic food consumers are known to place higher importance on geographical origin than average consumers (Hempel and Hamm, 2016; Janssen, 2018), while the opposite effect holds true for 'price'. Organic food consumers are less price sensitive than average consumers, in that organic food consumers pay relatively little attention to price (Lusk, 2011; Janssen, 2018). Therefore, we suggest the following hypothesis:

H3: For organic food consumers, 'geographical origin' has a stronger influence on wine choice than 'price'.

\section{Methods and materials}

To identify consumer segments for organic wine, a cross-sectional survey of 600 consumers was carried out. The computer-assisted survey consisted of choice experiments and a selfadministered questionnaire. The data were analysed with the methods of mixed logit models and latent class modelling.

\subsection{Sampling}

The participants were recruited at six grocery stores in different regions of Germany in autumn 2011, i.e. in the North (Hamburg, $n=101$ ), the Southwest (Mainz, $n=98$; Stuttgart, $n=99$ ), the East (Berlin, $n=100$ ), the West (Köln, $n=99$ ), and the middle (Kassel, $n=103$ ). Data collection was spread across the country since wine preferences - in particular regarding wine origin - were assumed to vary with geographical proximity to the German wine growing regions. The interviewers were instructed to approach every second customer who entered the store to rule out a subjective choice of study participants. Two screening questions were used to select study participants: 'Do you buy wine?', and if the answer was yes, the second question was 'How often do you buy organic food?'. Those respondents who were wine buyers and bought organic food at least occasionally (i.e. once in a fortnight) were invited to participate in the study on the spot, and were offered a 5 Euro allowance. Participants completed the choice experiments and the questionnaire themselves on the computer (computer-assisted selfinterviewing) to lower the interviewer bias and social desirability bias.

\subsection{Choice experiments}

Choice experiments are a method to analyse consumer preferences for single product attributes (Gao and Schroeder, 2009). In choice experiments, participants are asked to choose a product out of a set of alternative products with different attributes (Lusk and Schroeder, 2004). Choice experiments are based on Lancaster's Consumer Theory (Lancaster, 1966) according to which the utility consumers derive from a product stems from its single attributes. In contrast to other methods for analysing consumer preferences (e.g. contingent valuation, auctions), choice experiments have the advantage of resembling a real buying situation (Breidert et al., 2006).

In the present study, the participants were asked to make buying decisions for wine. They were instructed to imagine they wanted to buy wine of their preferred type and variety for everyday drinking. On a laptop screen, they were shown descriptions of three different wines among which they could choose (Figure 1). The three wines within a choice set differed with 
respect to price, country of origin, and production method (Table 1). The selection of attribute levels tested in the choice experiments was based on expert interviews.

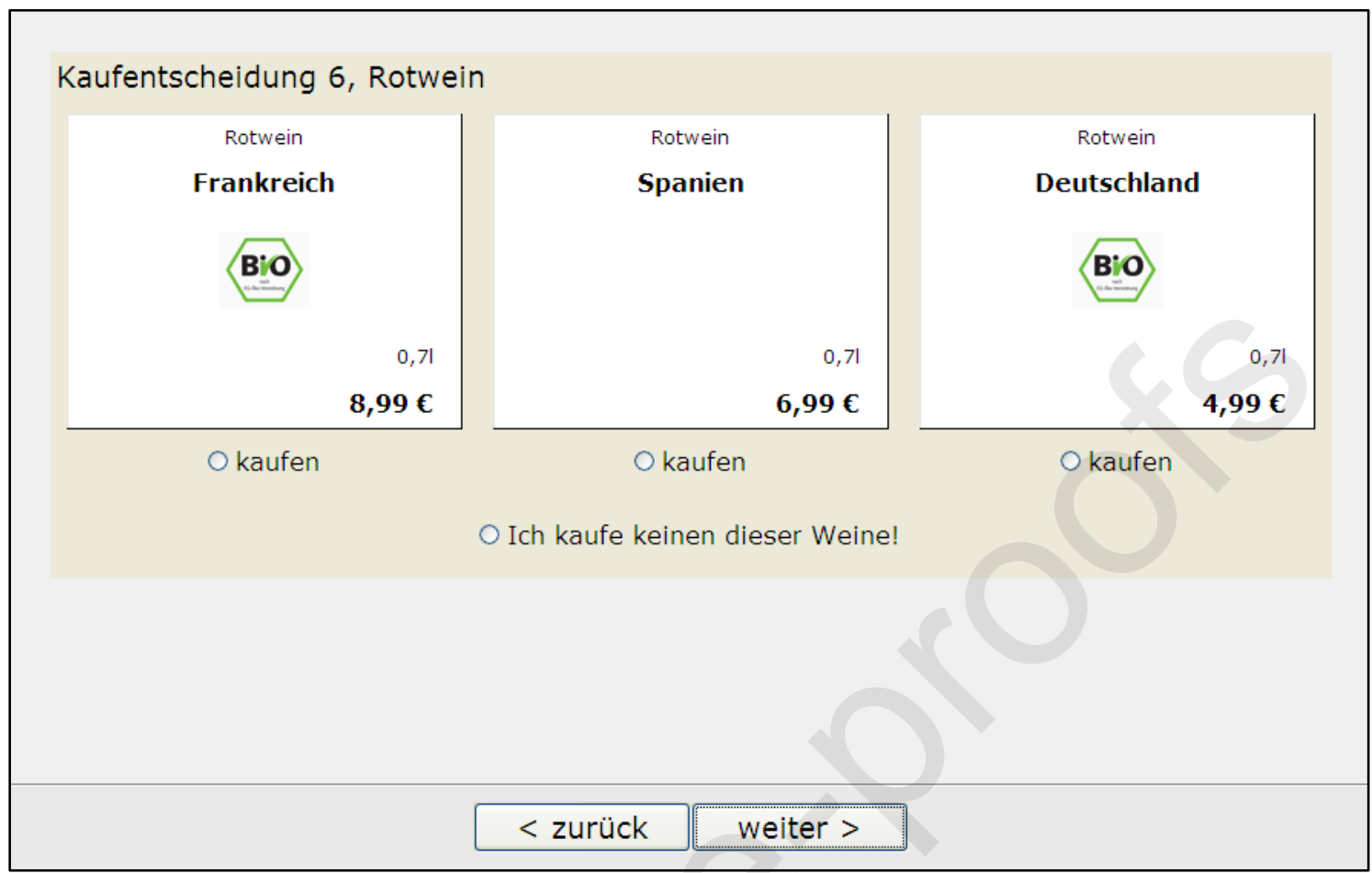

Figure 1: Example of a choice set

Table 1: Attributes tested in the choice experiments

\begin{tabular}{ll}
\hline Attributes & Attribute levels \\
\hline Country of origin & France, Germany, Italy, Spain \\
Production method & Organic, Conventional \\
Price & $2.99 €, 4.99 €, 6.99 €, 8.99 €$ \\
\hline
\end{tabular}

The systematic variation of the attribute levels across the different choice sets was based on a reduced d-optimal design with twelve different choice sets. Each participant completed four choice sets for red wine and four for white wine. In each choice set, the participants were also free not to buy any of the offered alternatives just like in a real purchase situation. This socalled no-buy option was offered to avoid a bias resulting from forced choices (Dhar and Simonson, 2003). To reduce the hypothetical bias (Lusk and Schroeder, 2004), the participants were instructed that one of the choices would be binding and they would have to pay for the wine they had chosen. The binding choice would be selected arbitrarily out of the eight choices each participant had made.

In the questionnaire subsequent to the choice experiments, data were collected on consumers' purchase behaviour regarding wine. As an estimator of the monthly wine consumption, the participants were asked how many bottles of wine they drink per month ('How much wine do you personally drink per month?' Answer box with the unit label 'bottles'). In the following question, they should estimate the percentage of organic wine in 
their total wine purchases (open-ended question). Afterwards, the participants were asked what would motivate them to buy more organic wine instead of conventional wine in the future (open-ended question with three answer boxes). In another question, they should estimate the percentage of red wine, white wine and rosé wine in their total wine purchases. At the end of the questionnaire, data on sociodemographic characteristics were collected.

\subsection{Econometric models}

Choice experiments are based on Random Utility Theory (Thurstone, 1987) postulating that consumers choose the product that provides them with the highest utility (Louviere et al., 2000; McFadden, 1974). The utility consumers derive from a product is divided into a deterministic and a random component, i.e. the utility of choosing product $j$ out of a choice set of $J$ products is composed of the observed utility $V_{j}$ and the random error term $\varepsilon_{j}$ capturing the unobserved utility. In the present study, the observed utility depended on the three product attributes country of origin, production method, and price:

$$
\begin{aligned}
& \text { (1) } U_{j}=\beta_{\text {France }} \text { France }+\beta_{\text {Germany Germany }}+\beta_{\text {Italy }} \text { Italy }+\beta_{\text {Spain }} \text { Spain } \\
& +\beta_{\text {organic }} \text { Organic }+\beta_{2.99} \text { Price } 2.99+\beta_{4.99} \text { Price } 4.99+\beta_{6.99} \text { Price } 6.99+\beta_{8.99} \text { Price } 8.99 \\
& +\varepsilon_{j}
\end{aligned}
$$

with $j=$ product 1, 2, 3 of three products offered within a choice set.

(2) $U_{\text {NoBuy }}=\beta_{\text {NoBuy }}$ NoBuy $+\varepsilon_{\text {NoBuy }}$

The attribute price was treated as a categorical variable (instead of a metric variable with a linear effect) since previous studies indicated that a strictly linear decreasing price-utilityfunction might not always be appropriate for analysing consumer preferences for wine (e.g. Bazoche et al., 2015; Chiodo et al., 2011; Lockshin et al., 2006; Mueller et al., 2010).

In the present study, the data collected in the choice experiments were analysed with two different methods, mixed logit models and latent class modelling. In both cases, separate models were estimated for red wine and white wine. The red (white) wine models included only those participants who had stated in the questionnaire subsequent to the choice experiments that they actually bought red (white) wine in reality (red wine: $N=571$, white wine: $\mathrm{N}=529$ ).

\section{Mixed logit models}

Mixed logit models represent a generalised form of traditional multinomial logit (MNL) models. While MNL models estimate fixed parameters, mixed logit models capture preference heterogeneity by estimating random parameters and providing estimates not only for the population mean but also for the standard deviation (Hensher et al., 2015). In mixed logit models, it can be determined whether a parameter is random or fix by checking whether the model provides a significant estimate of the standard deviation suggesting the parameter is random (Hensher et al., 2015). During the process of model specification, we checked all 
parameters for a significant standard deviation. We assumed the random parameters to be normally distributed.

A hybrid coding was used to capture the nested structure of the choice task, i.e. the no-buy option was effect coded, and the product attributes were dummy coded with one of the attribute levels as the reference category (Cooper et al., 2012). The mixed logit models were estimated with the software NLOGIT 4.0 (Econometric Software, 2016).

\section{Latent class modelling}

The method of latent class modelling (LCM) was applied for identifying different segments of wine consumers. LCM is a method for detecting homogeneous subgroups (called classes) within a heterogeneous population. In the present study, a latent class multinomial-logit choice model was estimated with the software Latent Gold Choice 5.1 (Vermunt and Magidson, 2014; Vermunt and Magidson, 2005). The segmentation of consumers was based on the choices the participants had made in the choice experiments. In addition, the following items from the questionnaire were added to the model as so-called inactive covariates, i.e. these variables did not influence the formation of classes but served as descriptors: 'monthly wine consumption (in litres)', and 'motivators for buying more organic wine instead of conventional wine in the future' in the form of the three dummy variables 'better availability and wider product range', 'improved taste', and 'lower prices'.

In latent class choice modelling, separate utility functions are estimated for each class (Chalak et al., 2008), where $U_{j / s}$ is the utility that consumers in class $s$ obtain from product $j$. The random error term $\varepsilon_{j / s}$ is assumed to be independently and identically distributed following a type I extreme value distribution (Chalak et al., 2008). The deterministic component $V_{j \mid s}$ is a linear function of attributes $X_{j}$ of product $j$, where $\beta_{s}$ is a vector of parameters for class $s$ (Chalak et al., 2008):

(3) $U_{j \mid s}=V_{j \mid s}+\varepsilon_{j \mid s}=\beta_{s} X_{j}+\varepsilon_{j \mid s}$

(4) $U_{\text {NoBuy } \mid s}=\beta_{\text {NoBuy } \mid s}$ NoBuy $+\varepsilon_{\text {NoBuy } \mid s}$

As suggested in the literature (Hensher et al., 2015), a set of models with different numbers of classes (one to eight classes) was estimated in the present study. The optimal number of classes was selected based on model fit statistics, i.e. $\mathrm{R}^{2}$ and the Bayesian Information Criterion (BIC). The BIC, also known as the Schwarz Criterion, is a criterion for model selection among a finite set of models; it balances the level of fit (quantified in terms of the loglikelihood) with model complexity. The model with the lowest BIC value should be preferred (Claeskens and Jansen, 2015).

For red wine, the 4-class model featured the lowest BIC value (see table provided in the supplementary material), and all classes had a class size of more than $10 \%$. The latter was seen important, since small class sizes might cause problems with insignificant parameter estimates difficult to interpret (Liljenstolpe, 2011). For white wine, the 3-class model had the lowest BIC value; however the 4-class model had an only slightly higher BIC value but a markedly higher $\mathrm{R}^{2}$ value (as an indicator of the goodness of model prediction). Accordingly, the Bootstrap 
procedure showed that the $\mathrm{R}^{2}$ value of the 4-class model represented a significant increase over the 3 -class model $(p=0.08)$. Also here, all classes had a class size of more than $10 \%$. Therefore, the 4-class solution was considered the optimal solution for both types of wine.

We detected significant differences between the preference structures of the four classes (regarding the attributes origin, price, organic production, and no-buy) based on paired comparisons with Wald tests (Vermunt and Magidson, 2005), and we mention significant differences in the description of results (section 4.3.). Unfortunately, the software Latent Gold Choice 5.1 does not offer the possibility to test for significant differences between classes for inactive covariates with Wald tests (Vermunt and Magidson, 2014; Vermunt and Magidson, 2005). In the description of results, we state whether a class has an above/below average value in the covariates but these figures should be interpreted with care. Still, we think the covariates offer some interesting insights.

\section{Results}

\subsection{Sample description}

The sample consisted of 600 consumers of which $65 \%$ were women (Table 2). In most households in Germany, women are still responsible for grocery shopping (Federal Research Institute of Nutrition and Food, 2008), so the high percentage of women in the sample seems plausible. The average age of 44 years in the sample corresponds with the average age in Germany (Statistisches Bundesamt, 2012). In line with previous studies on organic food consumers, highly educated people were overrepresented in the sample compared to the total population (Janssen, 2018; Janssen and Hamm, 2012; Zander and Hamm, 2010). 
Table 2: Sociodemographic characteristics of the sample

\begin{tabular}{|c|c|c|}
\hline & & $\%$ of participants \\
\hline \multirow{8}{*}{ Age $(N=600)$} & Mean: 44 yea & \\
\hline & $<25$ years & 7.2 \\
\hline & 25 - 34 years & 24.0 \\
\hline & $35-44$ years & 18.8 \\
\hline & $45-54$ years & 26.7 \\
\hline & 55 - 64 years & 13.8 \\
\hline & $65-74$ years & 7.7 \\
\hline & $\geq 75$ years & 1.8 \\
\hline \multirow{2}{*}{ Gender $(\mathrm{N}=600)$} & Women & 65.0 \\
\hline & Men & 35.0 \\
\hline \multirow{5}{*}{ Education $(\mathrm{N}=600)$} & $\begin{array}{l}\text { Highest level of formal } \\
\text { education: }\end{array}$ & \\
\hline & No formal qualification & 2.2 \\
\hline & $\begin{array}{l}\text { Secondary/Intermediate school } \\
\text { certificate }\end{array}$ & 16.2 \\
\hline & College/University entry qualification & 26.7 \\
\hline & College/University degree & 54.9 \\
\hline \multirow{7}{*}{ Household size $(\mathrm{N}=596)$} & Number of household members: & \\
\hline & 1 & 27.3 \\
\hline & 2 & 44.5 \\
\hline & 3 & 15.6 \\
\hline & 4 & 10.2 \\
\hline & 5 & 1.8 \\
\hline & 6 & 0.5 \\
\hline \multirow{10}{*}{ Income ( $\mathrm{N}=556)$} & Household net income per month: & \\
\hline & $<600 €$ & 5.0 \\
\hline & $600 €$ to $<1200 €$ & 11.0 \\
\hline & $1200 €$ to $<1800 €$ & 14.6 \\
\hline & $1800 €$ to $<2400 €$ & 18.0 \\
\hline & $2400 €$ to $<3000 €$ & 14.6 \\
\hline & $3000 €$ to $<3600 €$ & 10.1 \\
\hline & $3600 €$ to $<4200 €$ & 9.5 \\
\hline & $4200 €$ to $<4800 €$ & 6.8 \\
\hline & $4800 €$ and more & 10.4 \\
\hline
\end{tabular}

Regarding their monthly wine consumption, the participants stated to drink 2.5 litres of wine per month with a standard deviation of 2.3 (Table 3 ). The average monthly wine consumption of the participants was thus higher than the average of 1.7 litres in the German population in the same year (Deutsches Weininstitut, 2018), which is not surprising given the latter included also non-wine drinkers whereas the sample was limited to wine drinkers. In our sample, only $4.8 \%$ of the participants stated in the questionnaire that, in reality, they never bought red wine, while $11.8 \%$ stated they never bought white wine.

When being asked to estimate the percentage of organic wine in their total wine purchases in an open-ended question, the average share of organic wine amounted to $48.0 \%$ (Table 3 ). However, the high standard deviation of 35.7 demonstrated a high level of heterogeneity in the sample. The share of participants who stated to buy no organic wine but conventional wine exclusively amounted to $14.2 \%$, another $10.8 \%$ of the participants bought little organic wine (organic wine share of $1-10 \%$ ). Taken these two groups together, a quarter of the 
participants bought little or no organic wine, while only $15.7 \%$ of the participants stated to buy organic wine (almost) exclusively. This is an interesting finding demonstrating that almost $60 \%$ of the participants bought both, conventional and organic wine. When the participants were asked what would motivate them to buy more organic wine instead of conventional wine in the future (open-ended question with three answer boxes), the aspect of 'better availability and wider product range' was mentioned most often (mentioned by $36.5 \%$ of the participants), followed by 'lower prices' (31.1\%), and 'improved taste' (29.1\%).

Table 3: Stated (organic) wine consumption

\begin{tabular}{rc}
\hline Questionnaire items & \% of participants \\
\hline Wine consumption per month & Mean $=2.5$ litres (SD = 2.3) \\
less than 1 litre & 24.0 \\
1 to $<2$ litres & 24.0 \\
2 to $<3$ litres & 27.5 \\
3 litres or more & 24.4 \\
\hline Percentage of organic wine in total wine & Mean $=48.0 \%$ organic wine (SD = 35.7) \\
purchases & \\
0\% organic wine & 14.2 \\
1-10\% organic wine & 10.8 \\
11-30\% organic wine & 17.8 \\
31-50\% organic wine & 16.3 \\
51-70\% organic wine & 8.3 \\
71-90\% organic wine & 16.8 \\
91-100\% organic wine & 15.7 \\
\hline
\end{tabular}

What would motivate you to buy more organic wine instead of conventional wine in the future? ${ }^{1}$

Better availability and wider product range of organic wine

${ }^{1}$ This question was answered by 460 participants; participants who had stated to buy organic wine exclusively $(\mathrm{N}=81)$ were not asked this question, and 59 participants refused to answer it.

${ }^{2}$ Aspects mentioned by less than $10 \%$ of the participants were summarised under 'Other'.

\subsection{Mixed Logit Models}

Separate models were estimated for red and white wine. Both models were statistically significant at the $99.99 \%$ confidence level. The McFadden Pseudo R-squared value as an indicator of model fit amounted to 0.17 for red wine and 0.21 for white wine.

Table 4 shows the importance weights and the parameter coefficients of the attributes tested in the choice experiments. The importance weights indicate how strongly an attribute influenced the choice decisions in relation to the other attributes tested. For the choice of red wine, organic production was clearly the most important product attribute (importance weight of $62.8 \%$ ), while price and country of origin were of lower importance (importance weights of $22.6 \%$ and $14.6 \%$, respectively). For white wine, by contrast, the attributes organic production and country of origin both had a relatively strong influence on the choice decisions 
(importance weights of $45.1 \%$ and $38.9 \%$, respectively); again, price played a minor role (16.0\%).

While the importance weights of the attributes differed between the red wine and the white wine model, there were great similarities between the most preferred attribute levels for red wine and white wine (see parameter coefficients in Table 4). Regarding production methods, organic production was preferred over conventional production. Regarding price, wine at medium price levels ( $4.99 €$ and $6.99 €$ ) was preferred over low-priced wine at $2.99 €$, while $8.99 €$ was the least preferred price level (Table 4). The most preferred country of origin was Germany (as can be seen by the significant negative coefficients for the other three countries of origin in Table 4).

The results of the mixed logit models refer to the sample means, i.e. the average across all participants. For all attributes tested in the choice experiments, the mixed logit models revealed significant coefficient estimates for the standard deviations (Table 4) indicating a high degree of preference heterogeneity. 
Table 4: Mixed logit models on consumer preferences for wine attributes

\begin{tabular}{|c|c|c|c|c|c|c|c|}
\hline \multirow{3}{*}{ Attributes } & & \multirow{2}{*}{\multicolumn{3}{|c|}{ RED WINE }} & \multirow{2}{*}{\multicolumn{3}{|c|}{ WHITE WINE }} \\
\hline & & & & & & & \\
\hline & & $\begin{array}{l}\text { Importance } \\
\text { weights }\end{array}$ & Coefficients & p-values & $\begin{array}{l}\text { Importance } \\
\text { weights }\end{array}$ & Coefficients & p-values \\
\hline Production method & & $62.8 \%$ & & & $45.1 \%$ & & \\
\hline Reference: Conventional & Organic & & $1.80^{*}$ & .000 & & $1.97^{*}$ & .000 \\
\hline \multirow[t]{2}{*}{ Country of origin } & & $14.6 \%$ & & & $38.9 \%$ & & \\
\hline & France & & -0.24 & .054 & & $-1.82 *$ & .000 \\
\hline \multirow[t]{2}{*}{ Reference: Germany } & Italy & & $-0.26^{*}$ & .036 & & $-1.64^{*}$ & .000 \\
\hline & Spain & & $-0.91 *$ & .000 & & $-2.99 *$ & .000 \\
\hline \multirow[t]{2}{*}{ Price } & & $22.6 \%$ & & & $16.0 \%$ & & \\
\hline & $4.99 €$ & & $0.58^{*}$ & .000 & & $0.59 *$ & .000 \\
\hline \multirow[t]{2}{*}{ Reference: $2.99 €$} & $6.99 €$ & & 0.23 & .064 & & -0.26 & .119 \\
\hline & $8.99 €$ & & $-1.03^{*}$ & .000 & & $-1.09 *$ & .000 \\
\hline No-buy option & & & $0.26 *$ & .031 & & $-0.42^{*}$ & .001 \\
\hline \multirow{7}{*}{$\begin{array}{l}\text { Standard deviation of } \\
\text { random parameters }\end{array}$} & Organic & & $1.47^{*}$ & .000 & & $1.93^{*}$ & .000 \\
\hline & France & & $1.47^{*}$ & .000 & & $1.67^{*}$ & .000 \\
\hline & Italy & & $1.32 *$ & .000 & & $1.48^{*}$ & .000 \\
\hline & Spain & & $1.68^{*}$ & .000 & & $2.14^{*}$ & .000 \\
\hline & $4.99 €$ & & $0.78 *$ & .000 & & $0.94 *$ & .000 \\
\hline & $6.99 €$ & & $1.05^{*}$ & .000 & & $1.79 *$ & .000 \\
\hline & $8.99 €$ & & $1.75^{*}$ & .000 & & $2.00 *$ & .000 \\
\hline Mc Fadden Pseudo $\mathrm{R}^{2}$ & & & 0.17 & & & 0.21 & \\
\hline No. of observations & & & 571 & & & 529 & \\
\hline LL & & & -2633.226 & & & -2329.751 & \\
\hline
\end{tabular}

* Significant parameter coefficient $(p<0.05)$. 


\subsection{Latent class analysis}

The four-class solution turned out to be the optimal solution for red wine as well as for white wine. In both cases, four consumer segments with clearly distinct preference structures could be identified, as illustrated in Figure 2 .

\subsubsection{Red wine}

For red wine, the size of the four consumer segments ranged from $15.5 \%$ (class 4 ) to $39.3 \%$ (class 1 ). A relatively high R-squared value of 0.415 was achieved, indicating a good overall model fit (Table 5).

Three consumer segments with a strong preference for organic red wine were identified (classes 1, 2 and 3), while one consumer segment had a significantly lower preference for organic wine. Interestingly, only one consumer segment (class 3 ) gave organic production highest priority. The three segments with a preference for organic red wine had in common that they attached relatively little importance to the country of origin, but interesting differences were observed regarding the preferred price levels (Table 5).

\section{Class 1: Preference for medium-priced organic wine from France}

Consumers in the largest class 1 (class size: $39.3 \%$ ) based their choice of red wine mostly on the attribute price (importance weight of $28.9 \%$ ), closely followed by organic production (importance weight of 24.2\%). They preferred red wine at medium price levels of $4.99 €$ and $6.99 €$; in this respect they differed significantly from classes 2 and 3 . The preferred country of origin was France (importance weight of $12.0 \%$ ), constituting a significant difference to classes 3 and 4.

Class 1 consumers had an above average monthly wine consumption of 2.7 litres. When being asked what would motivate them to buy more organic wine instead of conventional wine in the future, class 1 consumers mentioned the aspect of 'better availability and wider product range' more often than 'improved taste' and 'lower prices'.

\section{Class 2: Preference for low-priced organic wine from France}

For class 2 consumers (class size: $28.7 \%$ ), the attribute 'price' was of even greater importance (importance weight of 43.3\%) than for class 1 consumers. Class 2 consumers, however, differed significantly from all other classes, in that they had a strong preference for low-priced red wine. Organic production was the second most important attribute (importance weight of $27.5 \%$ ). The country of origin was the least important attribute (importance weight of $14.7 \%$ ); also these consumers preferred French red wine, other than classes 3 and 4 (significant difference).

Class 2 consumers had a below average monthly wine consumption of 2.3 litres. In accordance with their choice behaviour in the experiments, class 2 consumers mentioned 'lower prices' of organic wine most often as motivating factors for buying more organic wine instead of conventional wine in the future. 
Class 3: Preference for organic wine at medium to high price levels

Class 3 (class size: 16.5\%) was the only consumer segment who gave organic production highest priority (importance weight of 33.1\%). Second most important was 'price' (importance weight of 20.4\%); class 3 consumers preferred red wine at medium and high price levels over low-priced wine, constituting a significant difference to classes 1 and 2. The country of origin did not have an influence on these consumers' choice of red wine (importance weight of 9.5\%); in this respect, class 2 differed significantly from all other classes. Also, class 3 consumers chose the 'no-buy option' significantly more often than the other classes, indicating their reluctance to make trade-offs when none of the three wines in the choice set had their desired combination of attributes.

Class 3 consumers had a below average monthly wine consumption of 2.3 litres. Similar to class 1 consumers, class 3 consumers mentioned 'better availability and wider product range' as the most important factor for increasing their organic wine purchases in the future.

\section{Class 4: Preference for German red wine}

Class 4 consumers had a significantly lower preference for organic wine than the other classes (class size: $15.5 \%$ ). Class 4 consumers based their choice of red wine primarily on the country of origin (importance weight of $60.3 \%$ ); they had a strong preference for red wine from Germany, constituting a significant difference to the other classes. Price and organic production were relatively unimportant to them (importance weights of $16.6 \%$ and $12.7 \%$, respectively).

Class 4 consumers had an average monthly wine consumption of 2.5 litres. When being asked what would motivate them to buy more organic wine instead of conventional wine in the future, class 4 consumers mentioned the aspects of 'better availability and wider product range', 'improved taste', and 'lower prices' almost equally often. 


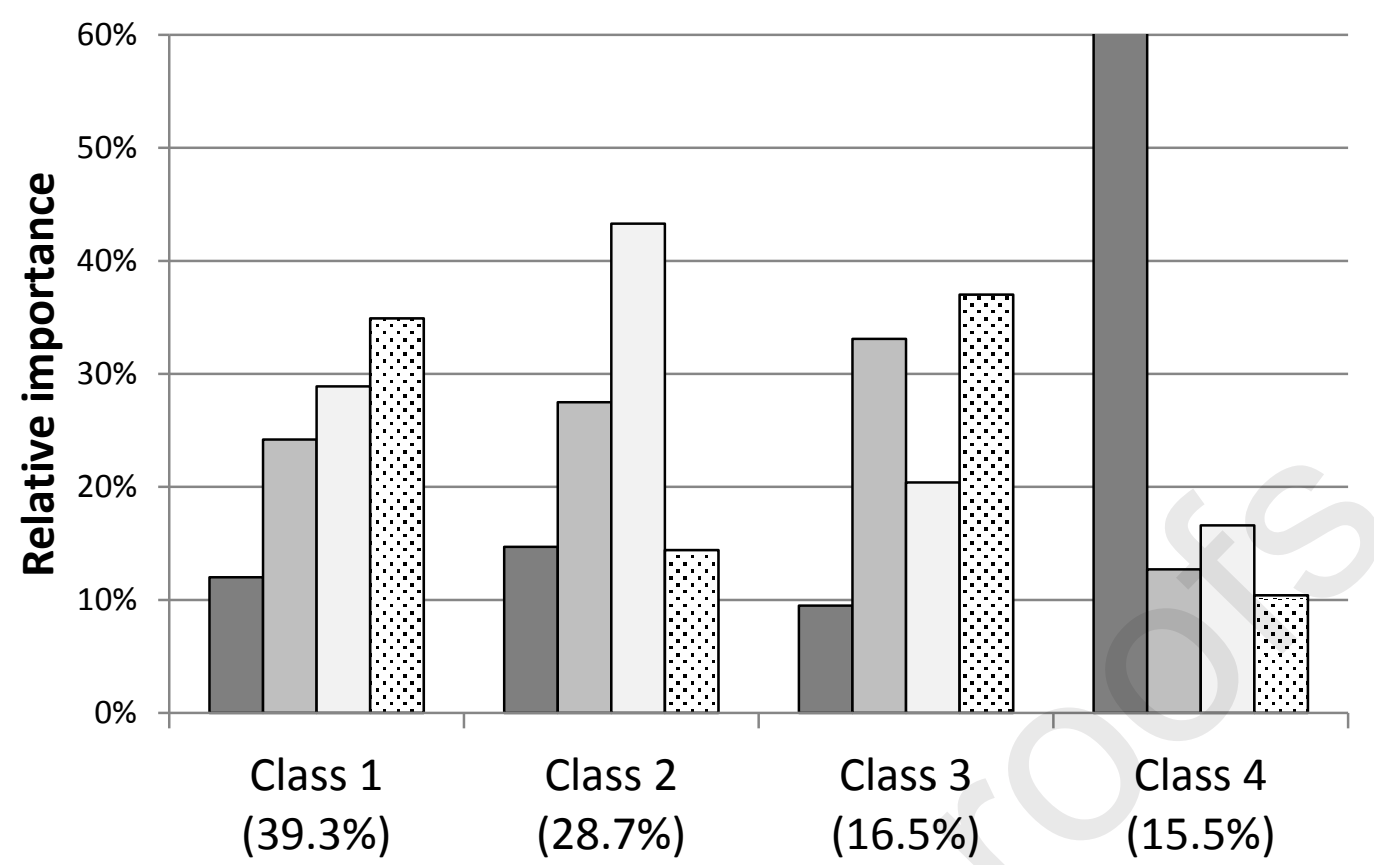

$\square$ Country of origin $\square$ Production method $\square$ Price $\square$ No-buy option

a)

Red wine $(\mathrm{N}=571)$

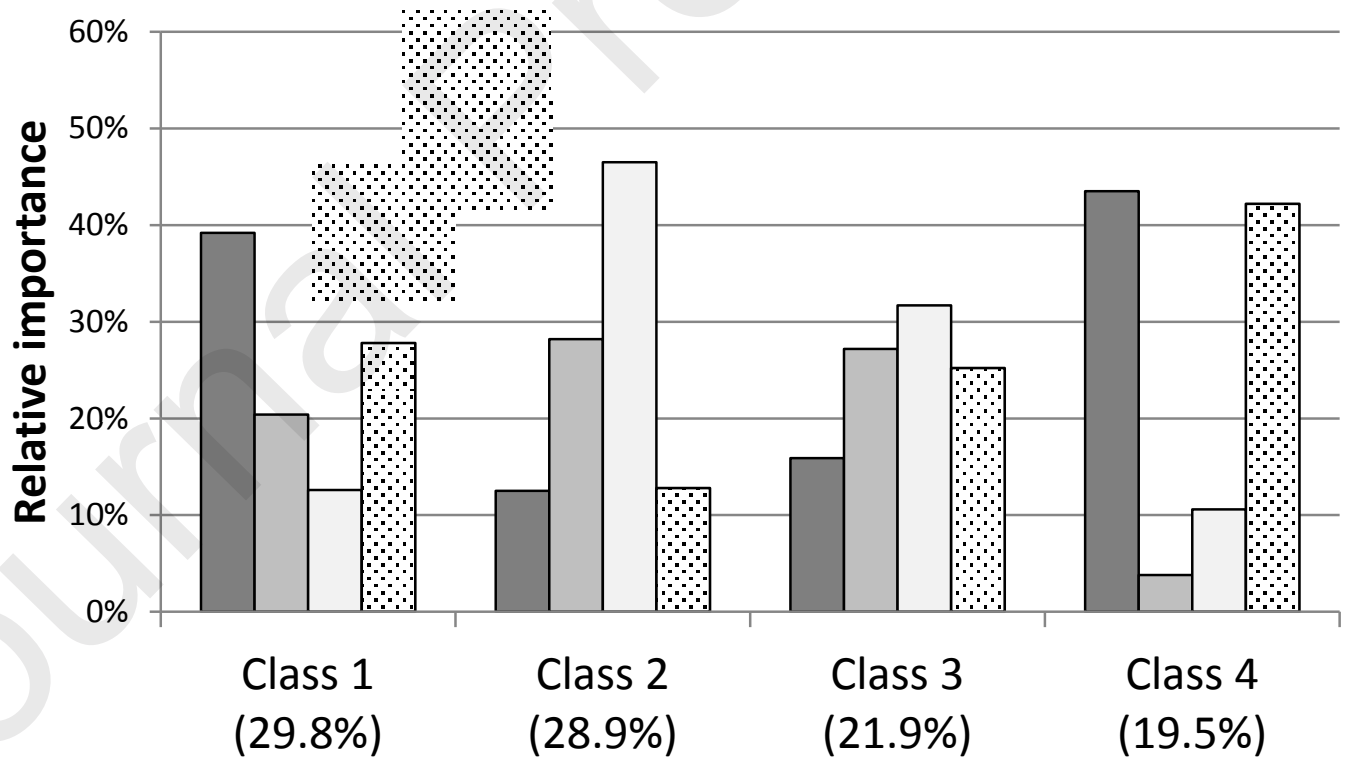

$\square$ Country of origin $\square$ Production method $\quad \square$ Price $\square$ No-buy option

b)

White wine $(\mathrm{N}=529)$

Figure 2: Relative importance of wine attributes across consumer segments 
Table 5: Latent class model on consumer segments for RED WINE

\begin{tabular}{|c|c|c|c|c|c|c|c|}
\hline RED WINE & & Class 1 & Class 2 & Class 3 & Class 4 & & \\
\hline Class Size $(N=571)$ & & $39.3 \%$ & $28.7 \%$ & $16.5 \%$ & $15.5 \%$ & \multicolumn{2}{|c|}{ Wald statistic $^{1}$} \\
\hline$R^{2}$ (Overall: 0.415$)$ & & 0.288 & 0.356 & 0.076 & 0.3139 & Wald(=) & $p$-value \\
\hline \multicolumn{8}{|l|}{ Parameter coefficients } \\
\hline \multirow[t]{4}{*}{ Country of origin } & Germany & $-0.38^{*}$ & $-0.47^{*}$ & 0.30 & $1.70 *$ & 85.89 & 1.10E-14 \\
\hline & France & $0.31^{*}$ & $0.38 *$ & -0.13 & -0.54 & & \\
\hline & Italy & 0.17 & 0.10 & 0.04 & -0.06 & & \\
\hline & Spain & -0.09 & -0.01 & -0.22 & $-1.10^{*}$ & & \\
\hline \multirow[t]{2}{*}{ Production method } & organic & $0.70 *$ & $0.80 *$ & $0.90^{*}$ & $0.30 *$ & 10.72 & 0.013 \\
\hline & conventional & $-0.70^{*}$ & $-0.80^{*}$ & $-0.90^{*}$ & $-0.30 *$ & & \\
\hline \multirow[t]{4}{*}{ Price } & $2.99 €$ & $-0.99 *$ & $1.13^{*}$ & $-0.76^{*}$ & -0.20 & 115.46 & $1.10 \mathrm{E}-20$ \\
\hline & $4.99 €$ & $0.53^{*}$ & $0.94^{*}$ & 0.14 & 0.32 & & \\
\hline & $6.99 €$ & $0.68^{*}$ & $-0.67 *$ & 0.35 & 0.33 & & \\
\hline & $8.99 €$ & -0.22 & $-1.39 *$ & 0.27 & -0.45 & & \\
\hline No-buy option & & $-2.00 *$ & $-0.84^{*}$ & $2.00 *$ & -0.48 & 210.28 & $2.50 \mathrm{E}-45$ \\
\hline Intercept & r & $0.53^{*}$ & 0.21 & $-0.34 *$ & $-0.40^{*}$ & 85.89 & $1.10 \mathrm{E}-14$ \\
\hline \multirow[t]{4}{*}{ Relative importance } & Country of origin & $12.0 \%$ & $14.7 \%$ & $9.5 \%$ & $60.3 \%$ & & \\
\hline & Production method & $24.2 \%$ & $27.5 \%$ & $33.1 \%$ & $12.7 \%$ & & \\
\hline & Price & $28.9 \%$ & $43.3 \%$ & $20.4 \%$ & $16.6 \%$ & & \\
\hline & No-buy option & $34.9 \%$ & $14.4 \%$ & $37.0 \%$ & $10.4 \%$ & & \\
\hline \multirow[t]{4}{*}{ Covariates $^{2}$} & $\begin{array}{l}\text { Monthly wine consumption (mean in litres) } \\
\text { Motivating factors for increased organic } \\
\text { wine purchases (in \% of participants): }\end{array}$ & 2.7 & 2.3 & 2.3 & 2.5 & & \\
\hline & Better availability and wider product range & $32.5 \%$ & $25.9 \%$ & $27.2 \%$ & $25.8 \%$ & & \\
\hline & Lower prices & $20.4 \%$ & $32.5 \%$ & $17.3 \%$ & $26.8 \%$ & & \\
\hline & Improved taste & $23.5 \%$ & $20.4 \%$ & $16.9 \%$ & $29.4 \%$ & & \\
\hline
\end{tabular}

* Significant parameter coefficient (Z-test, $\mathrm{p}<0.05)$.

${ }^{1}$ The $W$ ald $(=)$ statistic tests whether regression coefficients are equal between classes.

${ }^{2}$ The covariates were defined as 'inactive', i.e. they did not influence the formation of classes. 
Table 6: Latent class model on consumer segments for WHITE WINE

\begin{tabular}{|c|c|c|c|c|c|c|c|}
\hline WHITE WINE & & Class 1 & Class 2 & Class 3 & Class 4 & & \\
\hline Class Size $(N=529)$ & & $29.8 \%$ & $28.9 \%$ & $21.9 \%$ & $19.5 \%$ & \multicolumn{2}{|c|}{ Wald statistic $^{1}$} \\
\hline$R^{2}$ (Overall: 0.469) & & 0.214 & 0.438 & 0.330 & 0.304 & Wald(=) & p-value \\
\hline \multicolumn{8}{|l|}{ Parameter coefficients } \\
\hline \multirow[t]{4}{*}{ Country of origin } & Germany & $1.76^{*}$ & $0.35^{*}$ & 0.33 & $1.49 *$ & 84.07 & $2.50 \mathrm{E}-14$ \\
\hline & France & $-0.47^{*}$ & 0.04 & $0.44 *$ & -0.27 & & \\
\hline & Italy & -0.11 & 0.06 & -0.10 & 0.18 & & \\
\hline & Spain & $-1.18^{*}$ & $-0.46^{*}$ & $-0.67^{*}$ & $-1.40^{*}$ & & \\
\hline \multirow[t]{2}{*}{ Production method } & organic & $0.77^{*}$ & $0.90^{*}$ & $0.95^{*}$ & 0.13 & 43.15 & 2.30E-09 \\
\hline & conventional & $-0.77^{*}$ & $-0.90 *$ & $-0.95^{*}$ & -0.13 & & \\
\hline \multirow[t]{4}{*}{ Price } & $2.99 €$ & -0.19 & $1.32^{*}$ & $-1.38^{*}$ & -0.38 & 114.76 & $1.60 \mathrm{E}-20$ \\
\hline & $4.99 €$ & $0.45^{*}$ & $1.05^{*}$ & 0.37 & 0.33 & & \\
\hline & $6.99 €$ & 0.24 & $-0.70 *$ & $0.82 *$ & 0.26 & & \\
\hline & $8.99 €$ & $-0.50 *$ & $-1.67^{*}$ & 0.19 & -0.20 & & \\
\hline No-buy option & & $2.09 *$ & $-0.82^{*}$ & $-1.76^{*}$ & $-2.81^{*}$ & 249.27 & $9.40 \mathrm{E}-54$ \\
\hline Intercept & & 0.19 & 0.16 & -0.12 & -0.23 & 84.07 & $2.50 \mathrm{E}-14$ \\
\hline \multirow[t]{4}{*}{ Relative importance } & Country of origin & $39.2 \%$ & $12.5 \%$ & $15.9 \%$ & $43.5 \%$ & & \\
\hline & Production method & $20.4 \%$ & $28.2 \%$ & $27.2 \%$ & $3.8 \%$ & & \\
\hline & Price & $12.6 \%$ & $46.5 \%$ & $31.7 \%$ & $10.6 \%$ & & \\
\hline & No-buy option & $27.8 \%$ & $12.8 \%$ & $25.2 \%$ & $42.2 \%$ & & \\
\hline \multirow[t]{4}{*}{ Covariates $^{2}$} & $\begin{array}{r}\text { Monthly wine consumption (mean in litres) } \\
\text { Motivating factors for increased organic } \\
\text { wine purchases (in \% of participants): }\end{array}$ & 2.7 & 2.3 & 2.6 & 2.5 & & \\
\hline & Better availability and wider product range & $27.2 \%$ & $26.5 \%$ & $35.2 \%$ & $30.1 \%$ & & \\
\hline & Lower prices & $18.9 \%$ & $35.3 \%$ & $19.0 \%$ & $22.7 \%$ & & \\
\hline & Improved taste & $20.1 \%$ & $22.7 \%$ & $24.8 \%$ & $23.3 \%$ & & \\
\hline
\end{tabular}

* Significant parameter coefficient (Z-test, $p<0.05$ ).

${ }^{1}$ The Wald(=) statistic tests whether regression coefficients are equal between classes.

${ }^{2}$ The covariates were defined as 'inactive', i.e. they did not influence the formation of classes. 


\subsubsection{White wine}

For white wine (Table 6), the size of the four consumer segments ranged from $19.5 \%$ (class 4 ) to $29.8 \%$ (class 1 ). A high overall model fit was reached ( $\mathrm{R}$-squared value of 0.469 ).

Also in the case of white wine, three segments with a strong preference for organic wine were identified (classes 1, 2 and 3). However, none of the segments gave organic production highest priority. The three target groups for organic wine differed regarding the relative importance attached to the attributes country of origin and price (see Figure 2 and Table 6).

\section{Class 1: Preference for German organic white wine}

Consumers in class 1 (class size: 29.8\%) made their choice primarily based on the attribute country of origin (importance weight of 39.2\%); they had a strong preference for German white wine, constituting a significant difference to classes 2 and 3. Organic production was the second most important attribute (importance weight of 20.4\%). Price played a minor role (importance weight of 12.6\%); class 1 consumers preferred medium price levels of $4.99 €$ and $6.99 €$, again constituting a significant difference to classes 2 and 3 . Unlike consumers in other classes, class 1 consumers chose the 'no-buy option' significantly more often, i.e. they did not like to make compromises when none of the three wines in the choice set had their desired combination of attributes.

Class 1 consumers had an above average monthly wine consumption of 2.7 litres. They mentioned the aspect of 'better availability and wider product range' more often than 'improved taste' and 'lower prices' as potential factors motivating them to buy more organic wine instead of conventional wine in the future.

\section{Class 2: Preference for low-priced organic white wine}

Class 2 consumers (class size: $28.9 \%$ ) based their choice primarily on the attribute price (importance weight of $46.5 \%$ ). They had a strong preference for low-priced white wine; in this respect, they differed significantly from the other classes. The second most important attribute was organic production (importance weight of $28.2 \%$ ). The country of origin was of minor importance (importance weight of 12.5\%), constituting a significant difference to classes 1 and 4.

Class 2 consumers had a below average monthly wine consumption of 2.3 litres. Not surprisingly, class 2 consumers mentioned 'lower prices' of organic wine most often when being asked about what would motivate them to buy more organic wine instead of conventional wine in the future.

\section{Class 3: Preference for medium-priced organic white wine}

Class 3 consumers (class size: 21.9\%) made their choice mostly based on price (importance weight of $31.7 \%$ ) closely followed by 'organic production' (importance weight of $27.2 \%$ ). Class 3 consumers preferred medium and high price levels of $6.99 €$ and $8.99 €$ over low-priced wine, constituting a significant difference to the other classes. Similar to class 2 and 
significantly different from classes 1 and 4, the country of origin was of minor importance for class 3 consumers (importance weight of 15.9\%).

Similar to class 1 , class 3 consumers had a slightly above average monthly wine consumption of 2.6 litres and mentioned 'better availability and wider product range' as the most important factor for purchasing more organic wine instead of conventional wine in the future.

\section{Class 4: Preference for German white wine}

For class 4 consumers (class size: 19.5\%), the country of origin was by far the most important attribute (importance weight of $43.5 \%$ ) with Germany as the most preferred origin. Price was of low relevance (importance weight of 10.6\%). Regarding origin and price, class 4 differed significantly from classes 2 and 3 . Regarding production method, class 4 differed significantly from all classes, in that class 4 consumers attached no importance to organic production (insignificant coefficient).

Class 4 consumers had an average monthly wine consumption of 2.5 litres. Also this class mentioned 'better availability and wider product range' most often as a leverage for increasing their organic wine purchases.

\subsection{Overview of hypotheses}

In this section, we summarise the results of the hypotheses tests taking into account the results of both data analysis methods.

Hypothesis 1 - according to which the attribute 'organic' is more important than 'price' to organic food consumers - could be confirmed for red wine and white wine with the method of mixed logit models analysing sample means. Based on the results of the latent class analysis, however, hypothesis 1 could only be confirmed for one small consumer segment for red wine (class 3 ) and one large consumer segment for white wine (class 1 ) but needed to be rejected for the majority of participants. The different outcomes of the hypothesis test can be attributed to the high degree of preference heterogeneity with partly opposite preferences for the price levels tested. E.g. some consumers preferred low-priced wine while other consumers avoided it, so that 'price' had a rather weak influence in the mixed logit models.

Hypothesis 2 - according to which the attribute 'organic' is more important than 'geographical origin' for some segments, while the opposite holds true for other segments - could be confirmed for red wine as well as white wine in the latent class analysis (this hypothesis could not be tested with the mixed logit models).

Hypothesis 3 - according to which 'geographical origin' has a stronger influence on organic food consumers' wine choice than 'price' - could be confirmed for white wine but would need to be rejected for red wine according to the results of the mixed logit models. Based on the latent class analysis, hypothesis 3 could be confirmed for two consumer segments in the white wine model (classes 1 and 4), and one small segment in the red wine model (class 4). 


\section{Discussion}

The mixed logit models revealed a high degree of preference heterogeneity regarding the attributes organic, country of origin, and price. Accordingly, four consumer segments with clearly distinct preference structures could be identified in the latent class analysis. The following discussion of results is organised by the three product attributes investigated.

\section{Organic production}

Previous studies based on samples of consumers from the general population found that 'production method' only had a weak influence on consumer preferences (Bernabéu et al., 2008; Chiodo et al., 2011; Mann et al., 2012; Mueller Loose and Lockshin, 2013; Rahman et al., 2014; Schmit et al., 2013). The results of the present study suggested that 'organic' had a relatively strong influence on the wine choice of organic food consumers. However, it also needs to be emphasised that none of the consumer segments for white wine and only one small segment for red wine gave highest priority to organic production; in most consumer segments, 'organic' was only the second most important attribute with either price or country of origin being more important. Insofar, the findings of previous studies seem to hold true also for organic food consumers, namely that other attributes are more important than 'organic' (e.g. Bernabéu et al., 2008; Chiodo et al., 2011; Mann et al., 2012).

It is also worth mentioning that the results of the present study might be biased by socially desirable response behaviour. When the interviewers recruited participants for the present study, they asked them how often they bought organic food. This question might have influenced the choice behaviour in the subsequent experiments, and some people might have chosen organic wine simply because they thought it was socially desirable. Thus, it is likely that consumer preferences for organic wine are even slightly overestimated in the present study.

\section{Country of origin}

According to previous studies, 'origin' is among the most important wine attributes (e.g. Defrancesco et al., 2012; Jaeger et al., 2013; Mann et al., 2012; Yang and Paladino, 2015). Also in the present study, the choice of white wine was strongly influenced by the country of origin. Two consumer segments, encompassing half of the participants, made their choice primarily based on the country of origin; they clearly preferred white wine from Germany. The present findings for red wine, however, seem to contradict the findings of previous studies, in that the great majority of participants attached relatively little importance to the country of origin while the attributes 'price' and 'organic' were much more decisive.

\section{Price}

Regarding the preferred price levels for wine, there are mixed findings in the literature, even across studies which used similar research methods. Some studies found that consumers preferred wine at medium price levels over wine at low and high price levels (e.g. Bazoche et al., 2015; Chiodo et al., 2011; Lockshin et al., 2006; Mueller et al., 2010). Other studies, however, found that the lowest price level was most preferred (Bernabéu et al., 2008; Mann et al., 2012). The studies mentioned here all applied choice experiments or conjoint analysis; they were conducted in different countries and used different price levels and price ranges. It is 
known that the price levels and ranges included in such experiments might influence the respective results on consumers' price preferences, in that experimental designs with medium to high price levels might yield higher willingness-to-pay values than designs with low to medium price levels (Carlsson and Martinsson, 2008). However, we could not identify a systematic pattern across the studies cited here, that would explain the different results. But maybe the present study could provide an explanation. In our study, the mixed logit models representing the average preferences across the whole sample suggested a U-shaped priceutility function, i.e. wines at medium price levels were preferred over wines at low and high price levels. Interestingly, the latent class analysis revealed that one relatively large consumer segment ( $29 \%$ of the sample) had a different preference structure and clearly preferred lowpriced wine, while the other segments preferred medium-priced wine.

The latent class analysis revealed another interesting result regarding the importance of price compared to other product attributes. While organic food consumers generally pay little attention to food prices (Lusk, 2011; Janssen, 2018), about half of the participants (45\% for red wine and $50 \%$ for white wine) based their wine choice primarily on 'price'. For this part of the sample, our results confirm the findings by Bernabéu et al. (2008) and Chiodo et al. (2011), according to which price is the most important wine attribute for the majority of consumers. It is known that price acts as an important quality cue for consumers; consumers expect that more expensive wines are of higher quality than cheaper wines (Lockshin et al., 2006; Goldstein et al., 2008). Consumers use 'price' as a quality cue, in particular when few other quality cues are available (Zeithaml, 1988). It is interesting that also many organic food consumers in our study used 'price' instead of 'organic' or 'origin' as the most important quality cue for wine.

\section{Conclusions}

The present study provides important insights in two respects: first, in terms of consumers' wine preferences; and second, in terms of consumers' heterogeneous preferences and the importance of segmentation analysis.

\subsection{Consumers' wine preferences}

The present study analysed the wine preferences of organic food consumers to provide a better understanding of the role organic production plays when it comes to wine. The survey was conducted in 2011. We believe the findings from our study are still relevant and by no means outdated. In fact, the market share of organic wine in the total German wine market has been stagnating at around $5 \%$ since $2010^{2}$, so it seems the importance consumers attach to the attribute 'organic' has not changed remarkably over these years. The market shares of the four countries of origin we tested in the study have also been relatively stable over the past decade (Deutsches Weininstitut, 2014, 2018). The same holds true for the inflationadjusted consumer prices for wine (statista, 2019). This is not to say that consumer

\footnotetext{
${ }^{2}$ Own compilation based on GfK household panel data documented in Boller and Hamm (2018) and Schäufele and Hamm (2018).
} 
preferences and the wine market in general have not changed over the past decade. We only suggest that consumer preferences in terms of production method, country of origin, and price level have not changed remarkably.

The survey revealed that a quarter of the participating organic food consumers bought little or no organic wine, while only $15.7 \%$ stated to buy organic wine (almost) exclusively. The majority of participants were frequent buyers of both types of wine. When being asked what would motivate them to buy more organic wine instead of conventional wine in the future, the participants referred to the aspects of better availability and wider product range, lower prices, and improved taste of organic wine as the most important aspects. Interestingly, the vast majority of participants clearly preferred organic wine over conventional wine in the choice experiments. We argue this could be an indication for growth potential in the demand for organic wine. In the choice experiments, there was no difference between organic and conventional wines in terms of availability and price range; before the experiments, the participants were instructed to imagine they wanted to buy wine of their preferred type and variety. Apparently, consumers of organic food would buy more organic wine if their preferred type and variety of conventional wine would be available in organic quality at similar price levels.

While most consumer segments had a high preference for organic wine in the choice experiments, it also became clear that 'organic' was not the most important wine attribute for most consumer segments. The findings suggest that most organic food consumers use price or origin as quality cues for judging wine quality at the point of purchase. In this respect, organic food consumers do not seem to differ from non-organic consumers. At the same time, the present findings are good news for organic wine producers and retailers in that the latent class analysis revealed no consumer segment rejecting organic wine. Furthermore, the findings suggest that most consumers of organic food prefer wine at medium - or even high - price levels over low-priced wine.

Interestingly, the latent class analysis identified different target groups for organic wine who differed regarding their preferred price level and country of origin. The two most promising target groups are a smaller consumer segment with a high preference for organic wine and medium to high price levels (class 3 ), and a large consumer segment with a preference for organic wine, medium price levels, and above average wine consumption levels (class 1 ). This is good news for organic wine producers as well as retailers.

\subsection{Importance of segmentation analysis}

The present study also offers interesting conclusions for future consumer research. We analysed the choice experiment data with two different methods, i.e. mixed logit models providing estimates for the mean preference structure of the whole sample, and latent class models providing estimates for the preference structures of four consumers segments. The comparison between the results of the two methods highlights the importance of distinguishing between different consumer segments for wine. The latent class analysis identified four consumer segments with different (and partly opposite) preference structures which would have been overlooked if the analysis had only been based on mixed logit models. In fact, we would have concluded that organic is the most important wine attribute if we had 
conducted mixed logit models only. Through the subsequent latent class analysis, we know that this proposition might only hold true for a relatively small group of consumers.

At the same time, we acknowledge the importance of mixed logit models for providing an overview of the average preference structure and possible sources of preference heterogeneity. In some cases, distinct consumer segments do not exist, and then the method of latent class analysis is simply not appropriate nor meaningful. We conclude it seems advisable to approach choice experiment data with both methods (instead of relying on mixed logit models only, as it is often the case) - not only when it comes to wine but for all types of food products with heterogeneous consumer preferences.

\section{Acknowledgments}

We gratefully acknowledge funding from the Federal Ministry of Food and Agriculture (BLE) within the framework of the Federal Program for Organic Agriculture and other Forms of Sustainable Agriculture (BÖLN) (Grant no. 28100E087).

\section{References}

Aertsens, J., Verbeke, W., Mondelaers, K., \& van Huylenbroeck, G. (2009). Personal determinants of organic food consumption: A review. British Food Journal, 111(10), 11401167.

Baker, S., Thompson, K. E., and, J. E., \& Huntley, K. (2004). Mapping the values driving organic food choice: Germany vs the UK. European Journal of Marketing, 38(8), 995-1012.

Barreiro-Hurlé, J., Colombo, S., \& Cantos-Villar, E. (2008). Is there a market for functional wines? Consumer preferences and willingness to pay for resveratrol-enriched red wine. Food Quality and Preference 19(4), 360-371. https://doi.org/10.1016/j.foodqual.2007.11.004.

Bazoche, P., Issanchou, S., Brouard, J., Maratray, J., \& Ginon, E. (2015). Evaluating consumers' sustainable choice of wine: a virtual shop experiment. In: 143rd Joint EAAE/AAEA Seminar. Naples, Italy, March 25-27, 2015. http://purl.umn.edu/202735 (accessed 26.09.2018).

Bernabéu, R., Brugarolas, M., Martínez-Carrasco, L., \& Díaz, M. (2008). Wine origin and organic elaboration, differentiating strategies in traditional producing countries. British Food Journal $110,174-188$.

Boller, L., \& Hamm, U. (2018). Der Öko-Lebensmittelmarkt birgt noch viel Potenzial. bioPress 2018(1), 42-46.

Bonn, M.A., Cronin, J.J., \& Cho, M. (2016). Do environmental sustainable practices of organic wine suppliers affect consumers behavioral intentions? The moderating role of trust. Cornell Hospitality Quarterly, 57, 21-37.

Breidert, C., Hahsler, M., \& Reutterer, T. (2006). A review of methods measuring willingnessto-pay. Innovative Marketing, 2(4), 8-32. 
Brugarolas, M., Martinez-Carrasco, L., Bernabéu, R., \& Martinez-Poveda, A. (2010). A contingent valuation analysis to determine profitability of establishing local organic wine markets in Spain. Renewable Agriculture and Food Systems, 25, 35-44.

Carlsson, F., \& Martinsson, P. (2008). How much is too much? An investigation of the effect of the number of choice sets, context dependence and the choice of bid vectors in choice experiments. Environmental and Resource Economics, 40, 165-176.

Chalak, A., Balcombe, K., Bailey, A., \& Fraser, I. (2008). Pesticides, preference heterogeneity and environmental taxes. Journal of Agricultural Economics, 59(3), 537-554.

Chiodo, E., Casolani, N., \& Fantini, A. (2011). Evaluation of the effects of changes in regulatory policies on consumers perception: the case of designations of origin in the wine common market organisation. In: Paper Prepared for the EAAE 122nd Seminar. Ancona, Italy, February 17-18, 2011. http://purl.umn.edu/99590 (accessed 26.09.18).

Christ, K.L., \& Burritt, R.L. (2013). Critical environmental concerns in wine production. An integrative review. Journal of Cleaner Production, 53, 232-242.

Claeskens, G., \& Jansen, M. (2015). Model selection and model averaging. International Encyclopedia of the Social \& Behavioral Sciences (Second Edition), 2015, 647-652. https://doi.org/10.1016/B978-0-08-097086-8.42057-X.

Cooper,B., Rose, J., \& Crase, L. (2012). Does anybody like water restrictions? Some observations in Australian urban communities. The Australian Journal of Agricultural and Resource Economics, 56, 61-81. https://doi.org/10.1111/j.1467-8489.2011.00573.x.

D’Amico, M., Di Vita, G., \& Monaco, L. (2016). Exploring environmental consciousness and consumer preferences for organic wines without sulfites. Journal of Cleaner Production, 120, 64-71.

Defrancesco, E., Estrella Orrego, J., \& Gennari, A. (2012). Would 'New World' wines benefit from protected geographical indications in international markets? The case of Argentinean Malbec. Wine Economics and Policy 1, 63-72.

Deutsches Weininstitut (2014). Deutscher Wein - Statistik. https://www.deutscheweine.de/fileadmin/user_upload/Website/Service/Downloads/statistik _2014-2015.pdf (last accessed 27.08.2019).

Deutsches Weininstitut (2018). Deutscher Wein - Statistik. https://www.deutscheweine.de/fileadmin/user_upload/Website/Service/Downloads/Statistik _2018-2019.pdf (last accessed 27.09.2018).

Dhar, R., \& Simonson, I. (2003). The effect of forced choice on choice. Journal of Marketing Research, 40(2), 146-160.

Drennan, J., Bianchi, C., Cacho-Elizondo, S., Louriero, S., Guibert, N., \& Proud, W. (2015). Examining the role of wine brand love on brand loyalty: a multi-country comparison. International Journal of Hospitality Management, 49, 47-55. 
Econometric Software, Inc. (2016). LIMDEP and NLOGIT Software: Your Choice for Statistical Analysis. http://www.limdep.com/products/ (accessed 26.06.19).

EU Commission (2012). Regulation (EU) No 1151/2012 of the European Parliament and of the Council of 21 November 2012 on Quality Schemes for Agricultural Products and Foodstuffs.

Federal Research Institute of Nutrition and Food. (2008). National nutrition survey (II).

Karlsruhe.

https://www.mri.bund.de/fileadmin/MRI/Institute/EV/NVS II Abschlussbericht Teil $1 \mathrm{mit} \mathrm{Er}$ gaenzungsbericht.pdf (accessed 15.08.18).

Fotopoulos, C., Krystallis, A., \& Ness, M. (2003). Wine produced by organic grapes in Greece: using means-end chains analysis to reveal organic buyers' purchasing motives in comparison to the non-buyers. Food Quality and Preference 14(7), 549-566.

https://doi.org/10.1016/S0950-3293(02)00130-1.

Gao, Z. \& Schroeder, T.C. (2009). Effects of label information on consumer willingness-to-pay for food attributes. American Journal of Agricultural Economics, 91(3), 795-809.

Goldstein, R., Almenberg, J., Dreber, A., Emerson, J.W., Herschkowitsch, A., \& Katz, J. (2008). Do more expensive wines taste better? Evidence from a large sample of blind tastings. Journal of Wine Economics 3(1), 1-9. https://doi.org/10.1017/S1931436100000523.

Gracia, A., Barreiro-Hurle, J., \& Lopez-Galan, B. (2014). Are local and organic claims complements or substitutes? A consumer preferences study for eggs. Journal of Agricultural Economics, 65(1), 49-67.

Gustafson, C.R., Lybbert, T.J., \& Sumner, D.A. (2016). Consumer sorting and hedonic valuation of wine attributes: exploiting data from a field experiment. Agricultural Economics, 47, 91-103.

Hempel, C., \& Hamm, U., (2016). How important is local food to organic-minded consumers? Appetite 96, 309-18.

Hensher, D. A., Rose, J., \& Greene, W. A. (2015). Applied Choice Analysis (2nd edition). Cambridge: University Press.

Hoffmann, D., \& Szolnoki, G. (2010). Verbrauchereinstellungen zu Bioweinen in Deutschland. 33rd World Congress of Vine and Wine (OIV), Tiflis, 20.-27.06.2010.

Jaeger, S.R., Mielby, L.H., Heymann, H., Jia, Y., \& Frøst, M.B. (2013). Analysing conjoint data with OLS and PLS regression: a case study with wine. Journal of the Science of Food and Agricultural, 93, 3682-3690.

Janssen, M. (2018). Determinants of organic food purchases: Evidence from household panel data. Food Quality and Preference 68, 19-28.

Janssen, M., \& Hamm, U. (2012). Product labelling in the market for organic food: Consumer preferences and willingness-to-pay for different organic certification logos. Food Quality and Preference 25, 9-22. 
Kim, H., \& Bonn, M.A. (2015). The moderating effects of overall and organic wine knowledge on consumer behavioral intention. Scandinavian Journal of Hospitality and Tourism, 15, 295310.

Lancaster, K.J. (1966). A new approach to consumer theory. Journal of Political Economy, 74(2), 132-157.

Lernoud, J., \& Willer, H. (2018). Current statistics on organic agriculture worldwide: Area, operators, and markets. In: Willer, $\mathrm{H}$. and Lernoud, J. The world of organic agriculture statistics and emerging trends 2018, FiBL and IFOAM, Frick and Bonn, pp. 34-126.

Liljenstolpe, C. (2011). Demand for value-added pork in Sweden: A latent class model approach. Agribusiness, 27(2), 129-146.

Lockshin, L., Jarvis, W., d'Hauteville, F., \& Perrouty, J.-P. (2006). Using simulations from discrete choice experiments to measure consumer sensitivity to brand, region, price, and awards in wine choice. Food Quality and Preference 17(3-4), 166-178.

https://doi.org/10.1016/j.foodqual.2005.03.009.

Louviere, J.J., Hensher D.A., \& Swait, J.D. (2000). Stated choice methods: Analysis and applications. Cambridge: Cambridge University Press.

Lusk, J. L. (2011). External validation of the food values scale. Food Quality and Preference, 22, 452-462.

Lusk, J.L. \& Schroeder, T.C. (2004). Are choice experiments incentive compatible? A test with quality differentiated beef steaks. American Journal of Agricultural Economics, 86(2), 467-482.

Mann, S., Ferjani, A., \& Reissig, L. (2012). What matters to consumers of organic wine? British Food Journal, 114, 272-284.

Mariani, A., \& Vastola, A. (2015). Sustainable winegrowing: current perspectives. International Journal of Wine Research 7, 37-48.

McFadden, D. (1974). The measurement of urban travel demand. Journal of Public Economics, 3(4), 303-328.

Mueller Loose, S., \& Lockshin, L. (2013). Testing the robustness of best worst scaling for crossnational segmentation with different numbers of choice sets. Food Quality and Preference, 27, 230-242.

Mueller Loose, S. \& Remaud, H. (2013). Impact of corporate social responsibility claims on consumer food choice: a cross-cultural comparison. British Food Journal 115, 142-166.

Mueller, S., Osidacz, P., Francis, L. \& Lockshin, L. (2010). Combining discrete choice and informed sensory testing in a two-stage process: Can it predict wine market share? Food Quality and Preference, 21(7), 741-754.

Naspetti, S., \& Bodini, A. (2008). Consumer perception of local and organic products: Substitution or complementary goods. The International Journal of Interdisciplinary Social Sciences, 3(2), 111-121. 
Olsen, J., Thach, L., \& Hemphill, L. (2012). The impact of environmental protection and hedonistic values on organic wine purchases in the US. International Journal of Wine Business Research 24(1), 47-67. https://doi.org/10.1108/17511061211213783.

Padel, S., \& Foster, C. (2005). Exploring the gap between attitudes and behaviour: Understanding why consumers buy or do not buy organic food. British Food Journal, 107(8), 606-625.

Pagliarini, E., Laureati, M., \& Gaeta, D. (2013). Sensory descriptors, hedonic perception and consumer's attitudes to Sangiovese red wine deriving from organically and conventionally grown grapes. Frontiers in Psychology, 4, 1-7.

Panzone, L.A. (2014). Why are discounted prices presented with full prices? The role of external price information on consumers' likelihood to purchase. Food Quality and Preference, $31,69-80$.

Pomarici, E. \& Vecchio, R. (2014). Millennial generation attitudes to sustainable wine: an exploratory study on Italian consumers. Journal of Cleaner Production 66, 537-545.

Rahman, I., Stumpf, T., \& Reynolds, D. (2014). A comparison of the influence of purchaser attitudes and product attributes on organic wine preferences. Cornell Hospitality Quarterly, $55,127-134$.

Schäufele, I., \& Hamm, U. (2017). Consumers' perceptions, preferences and willingness-to-pay for wine with sustainability characteristics: A review. Journal of Cleaner Production, 147, 379394.

Schäufele, I., \& Hamm, U. (2018). Organic wine purchase behaviour in Germany: Exploring the attitude behaviour-gap with data from a household panel. Food Quality and Preference, 63, 111.

Schäufele, I., Pashkova, D., \& Hamm, U. (2018) "Which consumers opt for organic wine and why? An analysis of the attitude-behaviour link. British Food Journal 120(8), 1901-1914. https://doi.org/10.1108/BFJ-03-2018-0141

Schmit, T.M., Rickard, B.J., \& Taber, J. (2013). Consumer valuation of environmentally friendly production practices in wines, considering asymmetric information and sensory effects. Journal of Agricultural Economics, 64, 483-504.

Sellers, R. (2016). Would you pay a price premium for a sustainable wine? The Voice of the Spanish Consumer. Agriculture and Agricultural Science Procedia 8, 10-16.

Sogari, G., Corbo, C., Macconi, M., Menozzi, D., \& Mora, C. (2015). Consumer attitude towards sustainable-labelled wine: an exploratory approach. International Journal of Wine Business Research, 27, 312-328.

Soosay, C., Fearne, A., \& Dent, B. (2012). Sustainable value chain analysis - a case study of Oxford Landing from "vine to dine". Supply Chain Management: An International Journal 17(1), 68-77. https://doi.org/10.1108/13598541211212212. 
Statista (2018). Leading wine import markets worldwide in 2017.

https://www.statista.com/statistics/328253/global-market-leading-wine-importing-countriesbased-on-value/ (accessed 05.10.2018).

Statista (2019). Entwicklung der Verbraucherpreise von Wein in Deutschland in den Jahren 2000 bis 2018. https://de.statista.com/statistik/daten/studie/462531/umfrage/entwicklungder-verbraucherpreise-von-wein-in-deutschland/ (accessed 27.08.2019).

Statistisches Bundesamt (2012). Statistisches Jahrbuch 2012. Wiesbaden: Statistisches Bundesamt.

Stolz, H., \& Schmid, O. (2008). Consumer attitudes and expectations of organic wine: $16^{\text {th }}$ IFOAM Organic World Congress. Modena, Italy, June 16-20, 2008. http://orgprints.org/13974/.

Thurstone, L.L. (1987). Psychophysical analysis. The American Journal of Psychology, 100(3/4), 587-609.

United States Department of Agriculture (2000). National Organic Program. Title 7. Part 205. NOP, in: 65 FR 80637, Dec. 21, 2000.

Vecchio, R. (2013). Determinants of willingness-to-pay for sustainable wine: evidence from experimental auctions. Wine Economics Policy 2, 85-92.

Vermunt, J.K. \& Magidson, J. (2005). Latent GOLD 4.0 User's guide. Belmont, Massachusetts: Statistical Innovations Inc.

Vermunt, J.K. \& Magidson, J. (2014). Upgrade Manual for Latent GOLD Choice 5.0: Basic, Advanced, and Syntax. Belmont Massachusetts: Statistical Innovations Inc.

Wiedmann, K.-P., Hennigs, N., Behrens, S.H., \& Klarmann, C. (2014). Tasting green: an experimental design for investigating consumer perception of organic wine. British Food Journal, 116, 197-211.

Willer, H., Schaack, D., \& Lernoud, J. (2018). Organic farming and market development in Europe and the European Union. In: Willer, H. and Lernoud, J. The world of organic agriculture - statistics and emerging trends 2018, FiBL and IFOAM, Frick and Bonn, pp. 218-255.

Yang, Y., \& Paladino, A. (2015). The case of wine: understanding Chinese gift-giving behavior. Marketing Letters, 26, 335-361.

Zander, K., \& and Hamm, U. (2010). Consumer preferences for additional ethical attributes of organic food. Food Quality and Preference, 21, 495-503.

Zanoli, R., \& Naspetti, S. (2002). Consumer motivations in the purchase of organic food: A means-end approach. British Food Journal, 104(8), 643-653.

Zeithaml, V.A. (1988). Consumer perceptions of price, quality, and value: a means-end model and synthesis of evidence. Journal of Marketing 52(3), 2-22. 
Highlights

- Organic not the most important wine attribute for most organic food consumers

- Different segments have partly opposite preference structures for price and origin

- Growth potential for organic wine identified

- Comparison of two analysis methods for choice data provides interesting insights 